\title{
THE ELECTRIFICATION OF AMERICAN RAILROADS
}

\section{By Thomas Conway, Jr.,}

Instructor in Finance and Real Estate, University of Pennsylvania.

The most important problems confronting railway officials at the present time are the reduction of the costs of operation and the increase in the efficiency of the service. No undertaking is too vast and no expenditure too great if it can be shown that the results secured will increase the profits of the system. On every hand grades are being reduced, curves and grade crossings eliminated and cut-offs constructed in order that the cost of operation may be decreased. The methods by which traffic may be increased and the cost of its movement diminished are being carefully studied by railroad managers. Under such conditions it is little to be wondered at that the possibilities of using electric power upon our railroads should receive careful attention.

Electricity as a motive power in transportation work was introduced little more than a decade ago. The substitution of the new power for the cable line and the horse car upon our city streets entirely revolutionized urban transportation conditions. Not only did it makë the schedule much more rapid, but it made possible the introduction of larger cars and a general improvement of the system which was impossible with the former methods of propulsion. So successful was electric power for street railway work that within a very few years a network of lines was constructed extending from the large centers into the country in all directions. The development of these large interurban systems which for mechanical perfection and excellence of equipment and service rival the older steam railroads clearly demonstrated that electricity had reached the point where it was a formidable rival of the steam locomotive. It had demonstrated its ability to give satisfactory service under the most trying conditions and had made profitable the operation of lines which could not have escaped insolvency had they used the older form of power.

The steam railroads began to investigate closely the possibilities (266) 
which seemed to be open to them. The New York, New Haven and Hartford was the first road to adopt electricity for railroad work. Its traffic situation is rather peculiar. Extending through a densely populated country and having a passenger traffic out of all proportion to the average for the United States, the road approaches more closely to the interurban, in the similarity of its traffic conditions, than any other system in the country. Large sections of this line immediately contiguous to populous centers have been equipped to utilize electric power, and there is in operation upon this system an electric passenger service which is unsurpassed. The most recent converts to electric power have been the New York Central and the Pennsylvania Railroads. The former is expending seventy million dollars in electrifying that portion of its system immediately contiguous to New York City, upon which there is such a dense suburban traffic, while the Pennsylvania has completed and put into operation a third-rail electric line from Camden to Atlantic City, and is making rapid strides toward the electrification of the eastern end of the Long Island Railroad, which will play an important part in the New York terminal improvements now under construction. To the layman, therefore, the time does not seem far distant when electricity will displace steam as a motive power. The dirty, noisy steam locomotive will, it appears, be speedily relegated to the place occupied by historical relics.

The substitution of electricity for steam as a motive power will be made, not because of mere sentimental reasons, but because it has been sanctioned and approved by engineers and financiers after exhaustive investigation and inquiry. The change entails an enormous expense, requiring the issue of large amounts of new capital, which will result in a reduction in dividends or may even seriously impair the security of existing bonds if the new form o. propulsion does not bring about a material increase in earnings or a decided decrease in the expense of operation.

There were on June $30,1905,48,357$ locomotives in active service in the country. There are no accurate statistics showing the cost of this equipment. At the present time a freight or passenger locomotive costs about $\$ 15,000$. If we take into consideration, however, that a considerable portion of the equipment consists of shifting engines and other units of smaller size and of lower cost, it seems fair to conclude that it would cost in the neighborhood of $\$ 12,000$ 
per locomotive to duplicate the equipment now in service. At this figure the American railroads have invested $\$ 580,284,000$ in steam locomotives which would sooner or later be rendered useless if the change was made.

It is to be presumed, however, that the conversion would occur gradually. The steam locomotives as they wear out would be replaced by electric equipment, the cost of which would be taken out of the earnings of the property in the same manner as has been universally followed in the past. Under such conditions, therefore, it is fair to assume that, since an electric locomotive of the same tractive power and speed can be purchased for approximately the same amount now charged for a steam locomotive, the railroads would be able in a few years to convert their equipment without increasing the fixed charges on their properties. An examination of the annual reports of a number of the largest railroads indicates that about one-twentieth of the locomotives are renewed each year. It is likely, therefore, that the change of power could be made without an increase in the capitalization of the company in all cases except where the initial substitution of electricity is on a large scale as compared with the total rolling stock equipment of the railroad making the change.

It is claimed for the electric locomotive that it is much more effective and capable of more continuous use than the steam locomotive. The report of the Interstate Commerce Commission for I904 shows that the average effective train mileage, not including work trains, pushers or shifting mileage, was fifty-eight miles per locomotive per day. If an allowance is made for the items which were not included and for the use of double-headers and pushers where heavy grades are encountered, it seems fair to assume that the average daily run of a locomotive in the United States is about eighty miles. This figure, however, is a rough approximation. The performance of a passenger locomotive in long distance work will vary from ninety to nearly two hundred miles a day, and upon some lines high-speed engines will make as much as three hundred miles in twenty-four hours. The effectiveness of the locomotive is, however, much less pronounced in the other classes of service.

The recent investigations of the Interstate Commerce Commission have brought out the fact that the average locomotive is actually on the road not more than six hours in each twenty-four 
hour period. The remainder of the life of the locomotive is spent in yards and terminals, in making up trains, or awaiting an opportunity to take its place upon the main line. Almost one-third of each day is spent in the roundhouse, in order that the many small repairs which are constantly necessary can be made. The cleaning of boiler tubes, the inspection of the many bearings and journals and the adjustment of the complicated and delicate mechanism entail a heavy expense and occupy a large amount of time. The electric locomotive is very much more simple. It has the advantage of being capable of exerting its maximum tractive power upon very short notice. It is not necessary to occupy a large amount of time in firing up, and the repairs which must be made require less time and seem to be less expensive. It is urged, therefore, that the same number of electric locomotives will be much more effective than are those now in service.

There is little data available upon which to compare the relative cost of maintenance of electric and steam equipment. In 1904 the average expenditure for repairs per locomotive mile upon the steam equipment was 8.1 cents. The amounts spent by the leading lines using electric power are as follows: Manhattan Railway, 5 cents (estimated); New York Subway lines, 7 cents (estimated); WilkesBarre and Hazleton Railroad, 3.8 cents (actual); Lackawanna and Wyoming Valley Railroad, 8.4 cents (actual); the Niagara, Buffalo and Lockport Railroad, 7.9 cents (actual).

These comparisons, however, are not sufficient to warrant any general conclusions. In no case is it possible to secure a record of the performance of an electric locomotive as separated from the cost of repairing motors placed upon the trucks of passenger cars in the manner usually followed upon elevated, subway and interurban lines. The advocates of electric traction claim that it is possible to maintain an electric locomotive at a cost not exceeding $5 \frac{1}{2}$ cents per mile run. When we consider, however, that they are basing their estimates upon the cost of maintaining equipment which is practically new and which consequently requires little or no atten. tion, it seems advisable to conclude that the reduction in the maintenance cost of the new form of the equipment is not likely to play any important part in decreasing the cost of operation.

The production and transmission of power necessitates large and important expenditures. In addition to the cost of the power(269) 
house, which will vary with the volume of traffic and the character of the country, it is necessary to install a complete system of power distribution. The method which seems to be more generally favored is the third-rail system, using an alternating current with a voltage upon the rail ranging from 5,500 to II,O0O volts and with a feedwire potential in the neighborhood of 60,000 volts. The cost of such a system varies greatly. Not only does the amount of copper depend directly upon the severity of the demand which is placed upon the distributing system, but the great difference in the standards of overhead work makes very difficult any accurate estimate of the amount of money which would be necessary to electrify the railroads.

If a type of overhead construction similar to that which has been adopted by the New York, New Haven and Hartford and the New York Central is taken as a standard, there is little difference between the cost of an overhead trolley line and the third-rail system. A line equipped with No. 000 wire, with the type of insulator necessary to handle I I,000 volts, supported by steel cables and suspended from substantial steel bridges, set in concrete, spanning the tracks is fully as great as third-rail construction where steel poles are used to carry the feed wires. The cost of such work is approximately $\$ 10,300$ per mile where two tracks are to be equipped, while for single track work, using steel poles and brackets and catenary support, the cost, at the present time, closely approximates $\$ 4,800$ per mile. Of the 216,974 miles of railroads in operation in the United States in 1905 approximately four per cent is double track, including the yards and sidings for single-track lines. Upon this basis the average cost of overhead steel construction of the type considered would, therefore, average approximately $\$ 5,000$ per mile of track, entailing a total expenditure for the equipment of the mileage now in existence of $\$ 1,084,870,000$. In addition to this, it would be necessary to expend about $\$ 500$ per mile of track for bonding, which would add $\$ 108,487,000$ to the capital account of our railroads.

It is improbable, however, that such an expensive system of power distribution would be generally adopted. The average railroad would content itself with the use of wooden poles and a construction very similar to that followed upon the best interurban roads. It is very unlikely, however, judging from interurban ex- 
perience, that it would be possible for a railroad to install a satisfactory system of overhead work at a cost of less than $\$ 4,000$ per mile.

The weakness in a system of electric traction at the present time is not in the apparatus for the generation of power, nor in the electric locomotive, but is to be found in the power distributing system. The American types of dynamos and motors are so efficient that further improvements will have but little effect upon the cost of operation. The loss of power and energy occurs between the bus-bar on the switchboard and the motor. Even under the most favorable conditions it is necessary to develop about I 2-3 horse power in order to secure a horse power at the motor.

It is obvious that under such conditions the electric motor is badly handicapped. The steam engine is a direct connected machine, applying the power generated to the drivers with little or no waste. The loss of energy which occurs in the distributing system upon the electric line must, therefore, be overcome by the more effective method of power production which is possible in a plant where large condensing engines can be employed and where it is possible to use a type of boiler which will extract a greater amount of energy from a given weight of coal. The relative inefficiency of the locomotive comes about because of the necessity of using a high-pressure engine and a boiler which is relatively simple, since it must stand hard usage and rough treatment. There are no figures accessible showing the cost of power per horse power upon a locomotive. It is only possible to make a comparison by figuring the cost of moving the tonnage annually hauled by railroads and the approximate weight of the passengers and equipment which are handled under the two systems of propulsion.

Mr. Louis B. Stillwell and Mr. Henry Sinclair Putnam, in a paper read before the meeting of the American Institute of Electrical Engineers, held in New York in January of this year, submitted an elaborate calculation intended to ascertain the relative cost of electric and steam power for railroad work. According to their estimate, it would be possible to effect a very material saving in the cost of operation by using electric power. "If all the railroads of the United States were to-day operated by electricity, using the single phase alternating current system at the potential adopted for the equipment of the New York, New Haven and Hartford 
Railroad, the energy required for operation being developed by power plants such as are to-day in extensive use and transmitted at potentials well within the limits established in practical service, and if the rolling stock equipment consisted of locomotives and multiple unit trains fitted with motors and control apparatus, no better than the best which now exist, the aggregate cost of operation, which in 1905 amounted in round numbers to $\$ 1,400,000,000$, would be reduced by about $\$ 250,000,000 . "$

"In 1905 the average gross earnings of our railroads per mile of line were $\$ 9,598$, and the average operating expenses $\$ 6,409$. The foregoing calculation leads to the conclusion that high class electric equipment would reduce this average cost to $\$ 5,265$. The difference is $\$ I, I 44$ per mile of line, against which apparent saving must be charged the annual interest and depreciation of the power plant, the addition to permanent way equipment comprising overhead construction and track bounding, and the transmission circuits and the sub-stations with their equipment."

These conclusions were endorsed, in the main, by Mr. W. S. Murry, chief electrical engineer of the New York, New Haven and Hartford, and by the experts of the Westinghouse-Church-Kerr Company, and the General Electric Company. It seems fair to assume, therefore, that they are reasonably accurate. With this data as a starting point, the decision of the question as to whether or not the substitution of power will be profitable under presentday conditions is an accounting proposition. In order to operate the present service it will be necessary to have a chain of power plants capable of delivering a maximum output of abont 2,800,000 kilowatts which would cost approximately $\$ 400,000,000$. If we add to this $\$ 1.084,870,000$ as the cost of the distributing system, $\$ 108$,487,000 for the expense of bonding tracks, and $\$ 220,000,000$ for sub-stations, rearranging telegraph lines and special work in yards and terminals, we find that the change in power, exclusive of the cost of locomotives, which we will assume is gradually provided out of earnings, involves an expenditure of $\$ 1,8 \mathrm{r} 3,357.000$. If we allow the usual ten per cent rate of depreciation which has been found necessary in the case of the best interurban roads, it will be seen that the annual cost of maintenance of these items will be $\$ 181$,335,700 , while the saving effected by electrical traction will be only $\$ 250,000,000$. The saving in the cost of operation, therefore, 
because of the introduction of electric power would be $\$ 68,665,000$. In order to effect this saving it will be necessary to make an investment of between $\$ 1,800,000,000$ and $\$ 2,000,000,000$. If the railroads secure this morley by issuing four per cent bonds, which is about the lowest rate that it could be obtained for. even under the most favorable conditions, the annual interest charge would be between $\$ 72,000,000$ and $\$ 80,000,000$. If these calculations are correct the transformation of power would involve an increase in the total expenditure of between $\$ 8,000,000$ and $\$ 12,000,000$ per year. When we consider, moreover, that these results are based upon a period when the railroads are congested with traffic and when conditions prevail on every hand which are most favorable to demonstrating the economies of electric traction, it is easy to understand why railroad officials regard the results of electric operation as being extremely problematical. The effects of a decrease in the tonnage in lean years could be offset much less readily with the new form of power. Interest charges and depreciation would go on unchanged, while the cost of power production per kilowatt would steadily increase with the shrinkage in the amount consumed. The experience of the interurbans demonstrates that while the cost of operation per car-mile rapidly decreases with a growth in the bustness, yet the possibilities of cutting down expenses in periods of declining traffic are very limited. Electricity is pre-eminently the power upon lines where great traffic density prevails, but it compares poorly with steam where traffic is light and trains infrequent.

At the present time, therefore, it seems highly unlikely that electric power will be used except under special conditions and where the traffic is heavy. Most of our railroads are even yet in a halfdeveloped condition. It will be years before they will be able to show a traffic sufficiently dense to warrant the expenditure which is entailed in the installation of electric power. The success of the New York, New Haven and Hartford and of the New York Central, and the adoption of the third-rail system by the Pennsylvania for its Long Island service, marks the beginning of the use of electricity as a motive power upon lines where the passenger traffic constitutes a very important item. The operation of a large number of trains in small units is much less expensive with electricity than with steam, and in addition the provision of clean, attractive and quick service stimulates traffic to such a degree as to materially 
affect the earnings of the property. As the short distance passenger work increases we may expect to see a gradual substitution of electricity for steam upon the sections of our railroads contiguous to the large cities and towns.

Electricity will also play an important part upon the mountain divisions of our large systems. It is upon these stretches of track that we have the coincidence of water power and sharp grades. The production of the current in such sections can be carried on at a minimum expense. The electric locomotive possesses an immense advantage over the steam engine where a high maximum tractive work for a limited time is demanded. It is possible to force a locomotive far beyond its rated power for a few'minutes, but the boiler soon falls behind the demands which are made upon it, with the result that we have a reaction rendering the machine even less effective than it would be under normal conditions. An electric locomotive not only exerts its maximum power within a few seconds of the time it is put in operation, but it can be forced above its normal rate for long periods of time without materially affecting its performance. Experiments have shown that it is possible for an electric locomotive to go from twenty-five to fifty per cent above the rating, and in cases where the strain is only for a few minutes it has been possible to get out of them one hundred per cent more power than they were calculated to produce. When we compare these results with the possibilities of forcing steam operated machines and when we consider the extreme cheapness of power upon mountain divisions, we can readily understand why it is that so many of the large systems are taking steps to electrify these troublesome stretches of their roads. Electricity as a motive power has made very important strides, and has demonstrated its superiority where unusual conditions exist and where great density of traffic is encountered. The universal adoption of electricity, however, is a long way off. Not until a better system of power transmission has been devised or the traffic of our railroads has become much denser can we hope to see it generally adopted. 